\title{
An Assessment of the Effects of Micron-Particle Aggregation on the Performance of Zinc-Silica Composite Coatings Using Betti Numbers
}

\author{
Jianxin Xu, ${ }^{1,2}$ Xiuli Sang, ${ }^{1,2}$ Hua Wang, ${ }^{2}$ and Yunying Fan ${ }^{3}$ \\ ${ }^{1}$ Quality Development Institute, Kunming University of Science and Technology, Kunming 650093, China \\ ${ }^{2}$ Engineering Research Center of Metallurgical Energy Conservation and Emission Reduction Ministry of Education, \\ Kunming University of Science and Technology, Kunming 650093, China \\ ${ }^{3}$ Faculty of Materials Science and Engineering, Kunming University of Science and Technology, Kunming 650093, China
}

Correspondence should be addressed to Xiuli Sang; kmustsunny2008@126.com

Received 16 August 2013; Accepted 4 November 2013

Academic Editor: Wen-Hua Sun

Copyright (C) 2013 Jianxin Xu et al. This is an open access article distributed under the Creative Commons Attribution License, which permits unrestricted use, distribution, and reproduction in any medium, provided the original work is properly cited.

\begin{abstract}
This paper investigates the assessment of the mixing effect of zinc-silica composite electrolyte using particle image velocimetry (PIV). In particular, we considered the deposition of silica particles using a stirring tank, which provides strong evidence for characterizing the mixing effects of flow field. A method to extract meaningful parameters to evaluate particle distribution from digital images recorded by the PIV technique during the electrodeposition process is applied. The Betti numbers of binary images of silica particles mixing were calculated using the CHomP software, which was used to evaluate mixing homogeneity and nonhomogeneity in flow field. An analysis of the performance of zinc-silica composite coatings is performed in an attempt to test and verify the assessment of the effects of micron-particle aggregation. Good correlations between calculated and experimental testing results illustrate the potential of the Betti numbers method to quantitatively evaluate micron-particle aggregation. This offers new possibilities to monitor the deposition of silica particles and to analyze flow field during the electrodeposition progress.
\end{abstract}

\section{Introduction}

Composite electrodeposition, an important technology for metal surface treatments, is widely used to make metalmatrix composites and multifunctional composite cladding materials $[1,2]$. Its technical principle is as follows: tiny insoluble solid particles (micron- or nanometer-sized) are added to an electrolyte containing metallic ions; by stirring and mixing, these solid particles flow with the electrolyte and collide with a negative electrode; after the collision, they are adsorbed onto the surface of the negative electrode and react with the metallic ions in the electrolyte; finally, composite deposits begin to form. The electrodeposition technique, where solid particles constituting the composite phase are combined with the matrix metal, can improve the matrix metal's resilience to erosion, polishing, high-temperature oxidation, and other conditions. It can also be used to make self-lubricating coatings and electrical contact materials.
In the case of composite electrodeposition, stirring in flow field is the key factor affecting the mass transfer, adsorption, and deposition of the solid particles. To understand the basic theory of composite electrodeposition and thus optimize the parameters of the technique, it is essential to understand the flow characteristics of the electrolyte. Zielinski [3] presented a study of the effect of a constant magnetic field on the basic processes of cobalt-tungsten alloy electrodeposition. Krause et al. [4] investigated the effect of a magnetic field on the electrodeposition of Co with respect to the strength and orientation of the magnetic field. Stirring in the flow field was found to be the deciding factor of whether solid particles could successfully be transferred to the negative electrode. Specifically, it determines the contacting frequency between the solid particles and the negative electrode. It also decides the adsorption state of those particles and whether strong stirring will cause these particles to subsequently desorb from the negative electrode. 
TABLE 1: Determination of experimental parameters.

\begin{tabular}{|c|c|c|c|c|c|c|}
\hline $\begin{array}{l}\text { Density of } \\
\text { electrolyte }\end{array}$ & Density of $\mathrm{SiO}_{2}$ & Conductivity & Surface tension & Dynamic viscosity & Kinetic viscosity & $\begin{array}{l}\text { Average particle } \\
\text { size of } \mathrm{SiO}_{2} \\
\end{array}$ \\
\hline $1.16 \sim 1.18 \mathrm{~g} / \mathrm{cm}^{3}$ & $2.65 \mathrm{~g} / \mathrm{cm}^{3}$ & $0.75 \sim 0.95 \times 10^{3} \mu \mathrm{s} / \mathrm{cm}$ & $40.5 \sim 41.0 \mathrm{mN} / \mathrm{m}$ & $1.50 \sim 1.52 \times 10^{-3} \mathrm{~Pa} \cdot \mathrm{s}$ & $1.51 \sim 1.53 \times 10^{-6} \mathrm{~m}^{2} / \mathrm{s}$ & $11.07 \mu \mathrm{m}$ \\
\hline
\end{tabular}

Furthermore, it affects the deposition degree of solid particles and the deposition amount as well as the degree of uniform distribution, which eventually decides the structure, composition, and performance of the composite cladding material. The better the uniform distribution degree is, the better the capabilities of a composite cladding material are.

The flow state of the electrolyte and the electrochemical reaction on the surface of the negative electrode are two basic scientific questions concerning the composite electrodeposition technique. Currently, there have been numerous reports investigating the electrochemical reaction mechanism along with respective models of composite electrodeposition [512]. Khan et al. [13] reported a detailed study of $\mathrm{Zn}-\mathrm{SiO}_{2}$ nanocomposite coatings deposited from a zinc sulfate solution at $\mathrm{pH}$ 3. Xia et al. [14] studied Ni-AlN composite coatings using the pulse electrodeposition technique. Kim and $\mathrm{Oh}$ [15] studied Ni-CNT (carbon nanotube) composite coatings using electrodeposition. However, few studies have investigated the flow state of the electrolyte. For instance, to what extent can we control the stirring intensity and particle density to easily obtain a full suspending liquid? What effects do technical factors have on the mass transfer of the suspending liquid? Which kind of flow field can achieve effective adsorption of solid particles? How can the rate of particle desorption from the negative electrode surface be decreased? How can the deposition amount and distribution of particles over the metal surface be accurately and effectively controlled to obtain composite coating materials with optimal properties [16-19]? Research on this topic thus far has been unable to provide a quantitative interpretation or to even quantitatively define the technical parameters based on composite electrodeposition theory.

This study mainly focuses on the mixing effect of electrodeposition flow field. By adopting the evaluation method of Betti numbers; the mixing effect can be effectively quantified under different stirring conditions. Finally, by analyzing the capabilities of the resulting cladding material, the effectiveness of the evaluation method and the models of the multiphase mixing effect are verified.

\section{Experimental Study}

2.1. Experimental Determination of Relevant Parameters. The electrodeposition experiment was performed in a flat rectangular plexiglass tank, of dimensions $150 \mathrm{~mm}$ length, $100 \mathrm{~mm}$ width, and $120 \mathrm{~mm}$ height. The tank was filled with electrolyte up to a height of $100 \mathrm{~mm}$ when the stirring paddle remain stationary.. A vertical plate was used for the electroplating with a temperature of $25^{\circ} \mathrm{C}$. The composition of the electrolyte was $\mathrm{ZnCl}_{2} 80 \mathrm{~g} / \mathrm{L}, \mathrm{KCl} 220 \mathrm{~g} / \mathrm{L}, \mathrm{H}_{3} \mathrm{BO}_{3} 25 \mathrm{~g} / \mathrm{L}$, luster-coating agent $0.5 \mathrm{~g} / \mathrm{L}$, and $\mathrm{SiO}_{2} 1 \sim 6 \mathrm{~g} / \mathrm{L}$. The $\mathrm{pH}$ of this electrolyte was 5.5. Zinc chloride solution was chosen as the base fluid.

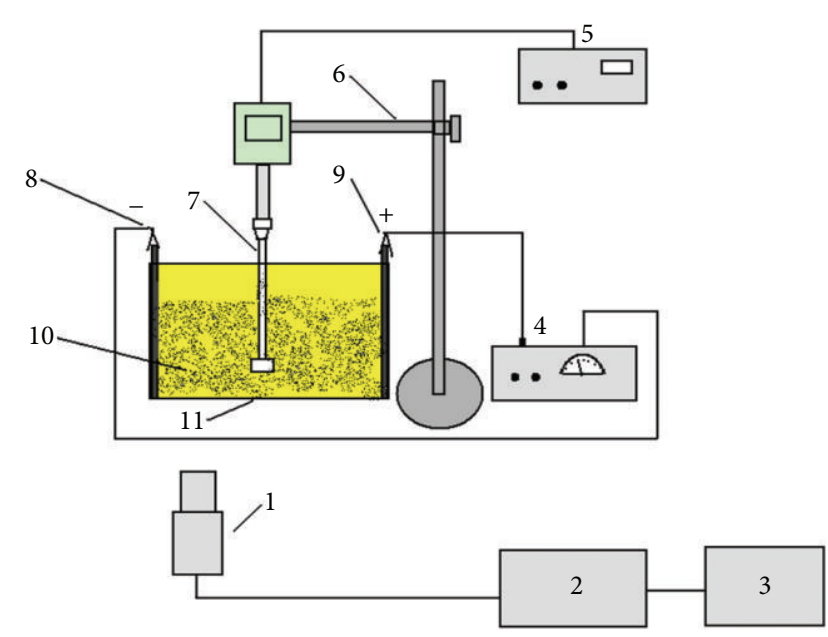

FIGURE 1: Experimental setup of electrodeposition ((1) camera, (2) image acquisition card, (3) computer, (4) electrodeposition device, (5) numerical control stirrer, (6) trestle, (7) stirring paddle, (8) negative electrode (iron), (9) positive electrode (zinc), (10) electrolyte, and (11) stirring tank).

The sizes of the $\mathrm{SiO}_{2}$ particles were around $10 \mu \mathrm{m}$. Particle concentration was below $10 \mathrm{~g} / \mathrm{L}$.

A viscometer was used to measure the viscosity of the electrolyte. The weighing method was adopted to determine the density of the electrolyte. A laser particle size analyzer was used to determine the distribution of the $\mathrm{SiO}_{2}$ particle size and the dispersion characteristics in the suspending fluid. Solution conductivity was measured using a conductivity meter. Surface tension was determined using a surface tension tester. The testing results are shown in Table 1.

2.2. Experimental Setup. The stirring rate of the electric stirrer was kept in the range of $0-3000 \mathrm{r} / \mathrm{min}$. The electric current of the electrodeposition device was $0-0.5 \mathrm{~A}$. The size of the stirring paddle was $2 \times 10 \times 6 \mathrm{~mm}$. The paddle was $10-30 \mathrm{~mm}$ high. A zinc plate functioned as the positive electrode while the negative electrode was composed of iron. The camera's field of view around the negative electrode was $100 \mathrm{~mm}$ high and $70 \mathrm{~mm}$ wide. The camera and computer were linked by an image acquisition card, which stored the real-time stirring pictures (Figure 1).

\section{Betti Numbers}

From algebraic topology, Betti numbers are defined as follows: $\beta_{0}$ is the number of connected components; $\beta_{1}$ is the number of one-dimensional or "circular" holes. In brief, $\beta_{0}$ represents the block number of the $2 \mathrm{D}$ image while $\beta_{1}$ represents the hole number of the $2 \mathrm{D}$ domain [20-23]. 


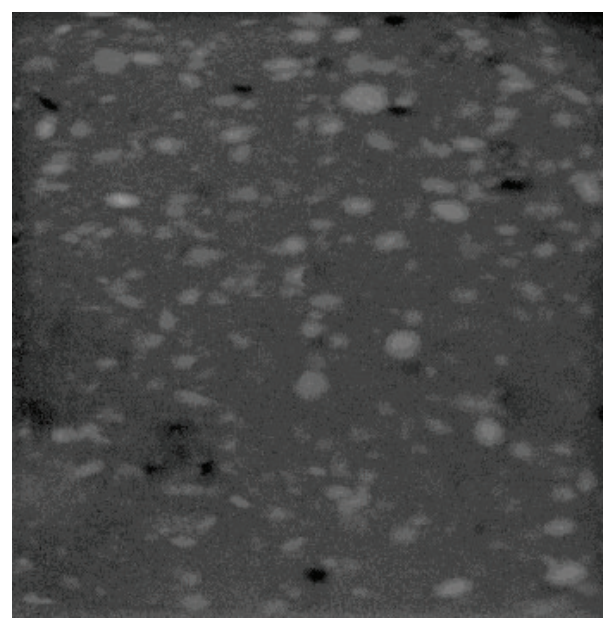

(a)

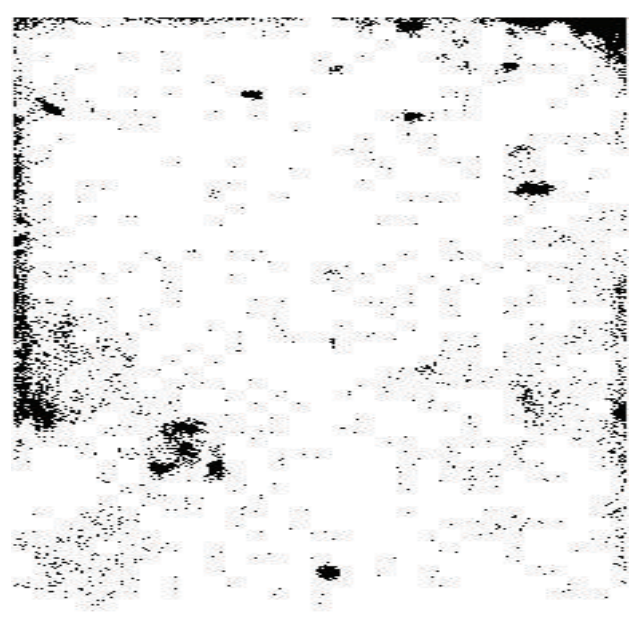

(b)

FIGURE 2: Mixing image and binary image in electrodeposition.

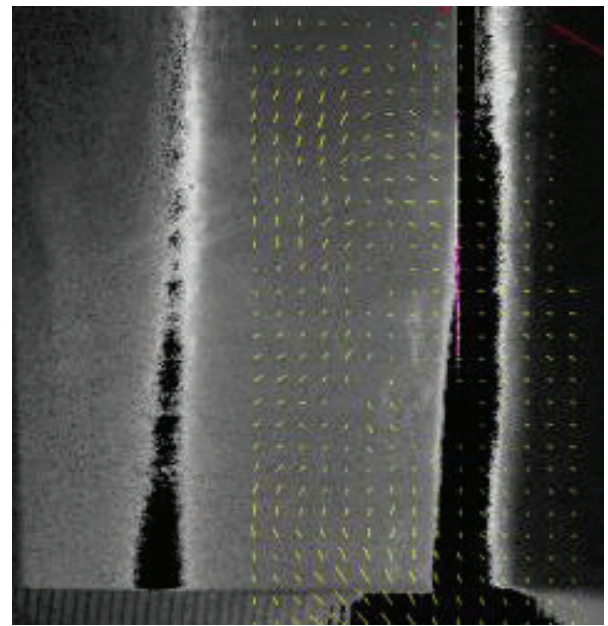

$(I=0 \mathrm{~A})$

(a)

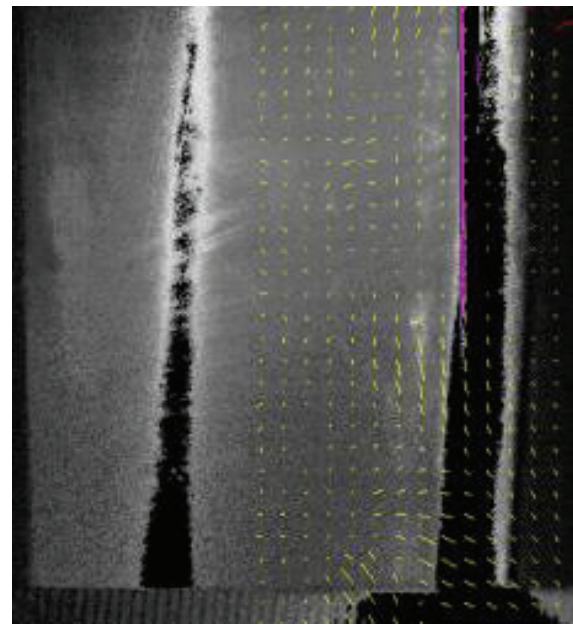

$(I=0.5 \mathrm{~A})$

(b)

FIGURE 3: Velocity distribution at $\bar{v}=100 \mathrm{r} / \mathrm{min}, h=10 \mathrm{~mm}$, and $t=100 \mathrm{~s}$.

The more blocks found in any plane inside the stirred reactor, the better the stirring of the mixture. Phenomena such as caking and aggregation occur during the mixing process and holes can be present in the agglomeration, the extent of which reflects the degree of nonuniformity of the mixing between the different phases inside the reactor. Hence, it is theoretically feasible to use $\beta_{0}$ and $\beta_{1}$ to parameterize the uniformity and nonuniformity of the mixture, respectively. Parameters such as the zeroth Betti number $\beta_{0}$, the first Betti number $\beta_{1}$, and their averages are calculated from the binary images of the patterns at different rotating speeds and paddle heights using the free software package CHomP [24].

Digital image processing technology was used to process the real-time images of mixing particles in flow field into binary images. The extracted Betti numbers are adopted to quantify the mixing effect in flow field.
In Figure $2, \beta_{0}$ is 1149 and $\beta_{1}$ is $144 . \beta_{0}$ is used to quantify the homogeneity of multiphase mixing while $\beta_{1}$ is used to quantify the heterogeneity. As there is a large amount of $\mathrm{SiO}_{2}$ particles, particle aggregation occurs with stirring as shown in the image of Figure 2. The aggregation penetrates all the stirring process. By calculating the Betti numbers of these images, the micron-particle aggregation may be effectively quantified.

\section{Results and Discussion}

4.1. Effect of Electrical Field on Micron-Particle Aggregation. The effect of electrical field on the micron-particle aggregation is now taken into consideration. The stirring paddle's height is kept at $10 \mathrm{~mm}$. With the same initial conditions, the particle image velocity (PIV) is calculated at $t=100 \mathrm{~s}$ and 


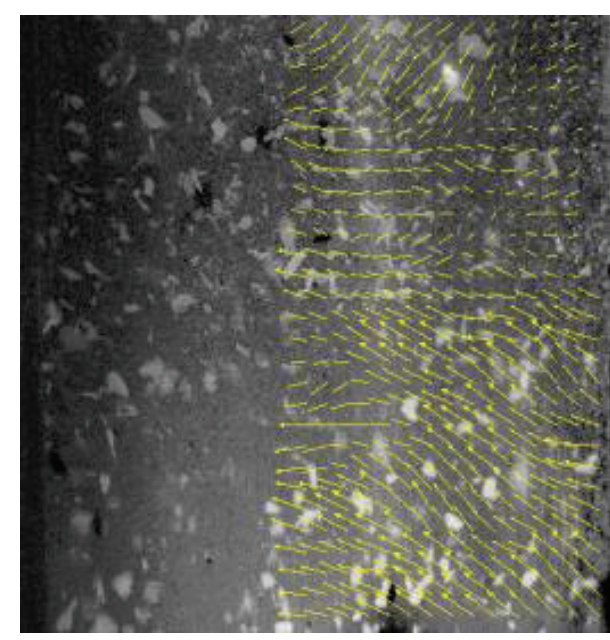

$(I=0 \mathrm{~A})$

(a)

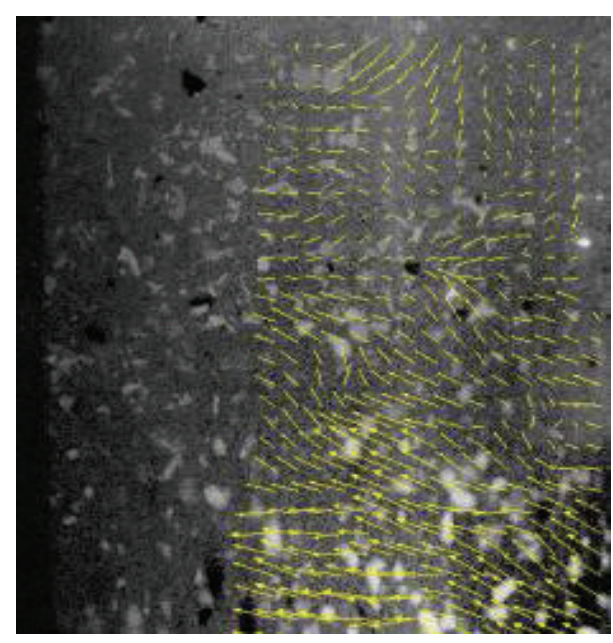

$(I=0.5 \mathrm{~A})$

(b)

FIGURE 4: Velocity distribution at $\bar{v}=1000 \mathrm{r} / \mathrm{min}, h=10 \mathrm{~mm}$, and $t=100 \mathrm{~s}$.

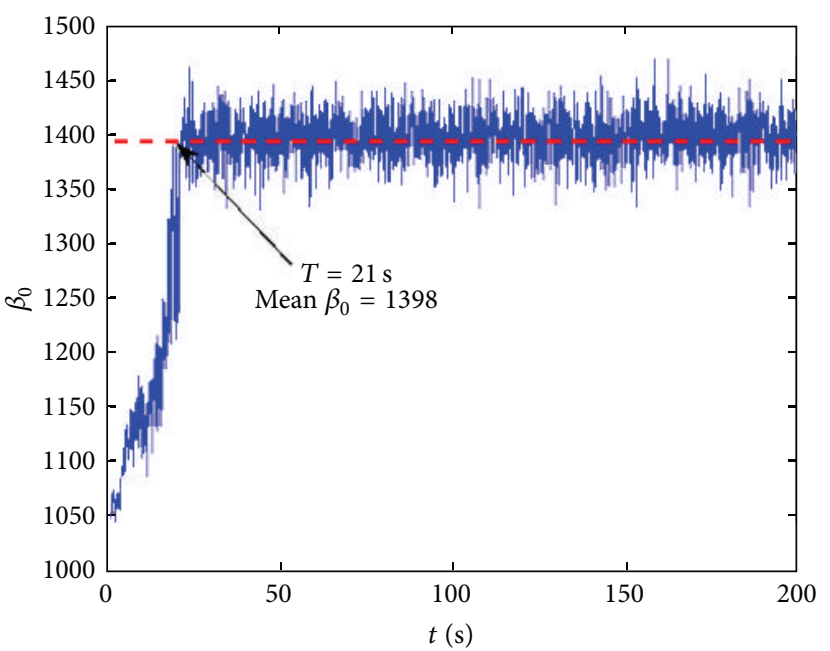

$v=1000 \mathrm{r} / \mathrm{min}, l=10 \mathrm{~mm}$

(a)

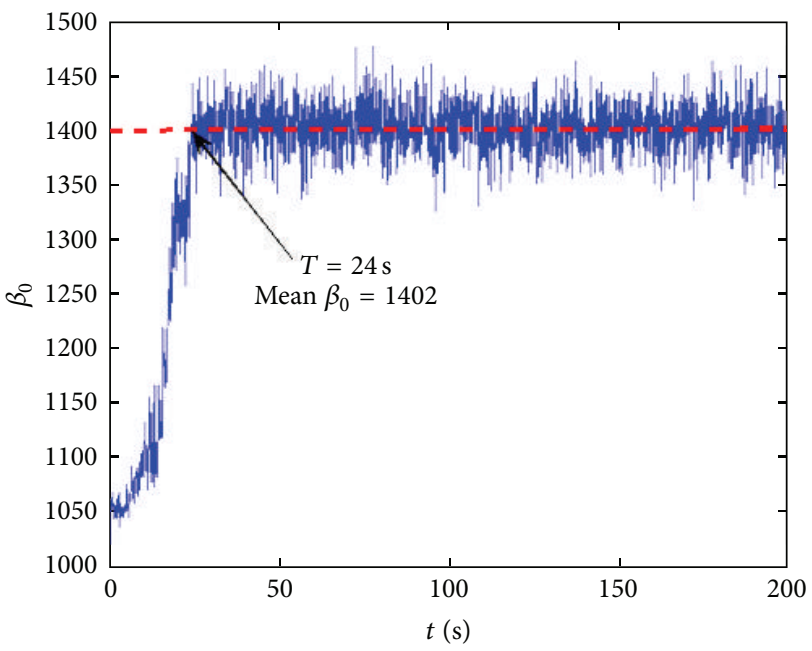

$v=2000 \mathrm{r} / \mathrm{min}, l=10 \mathrm{~mm}$

(b)

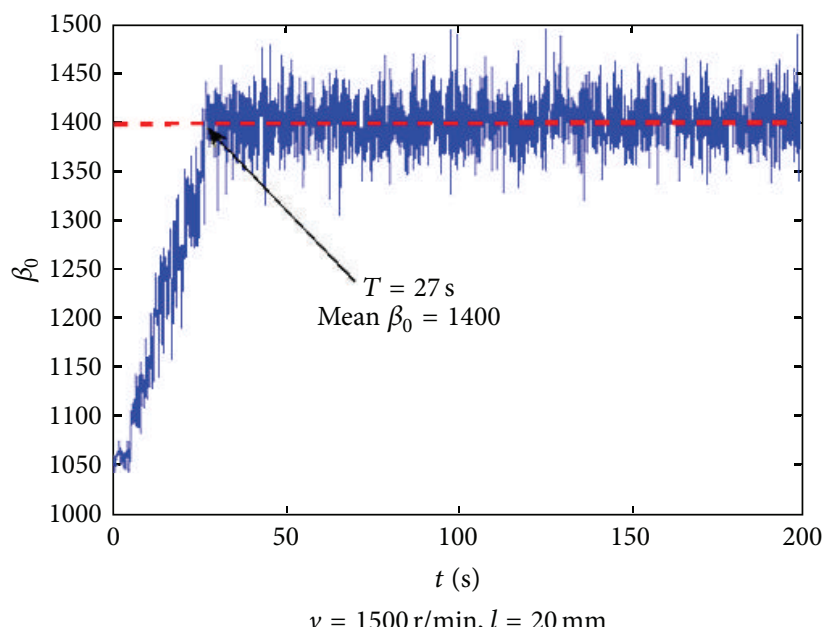

(c)

FIgURE 5: Evolution curves of 0-dimensional Betti numbers. 


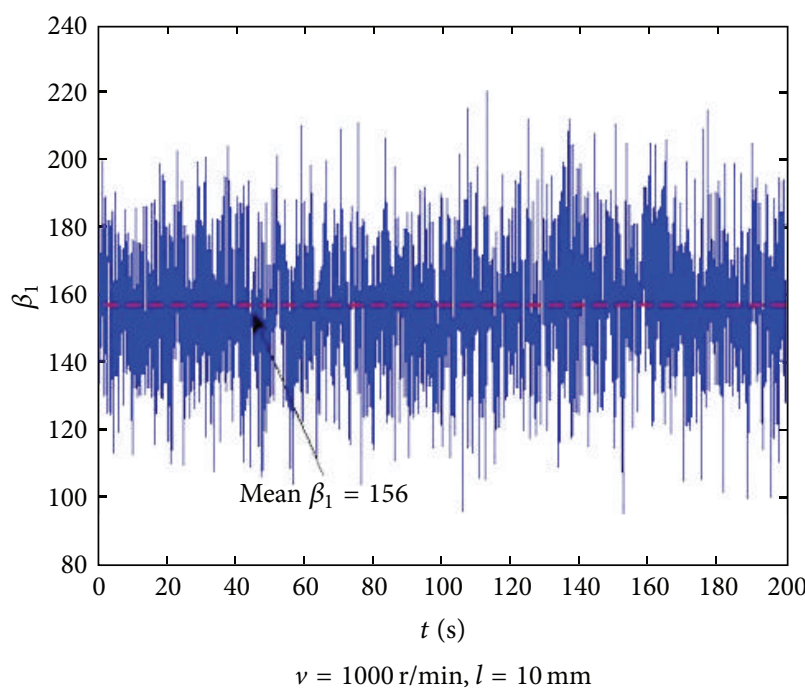

(a)

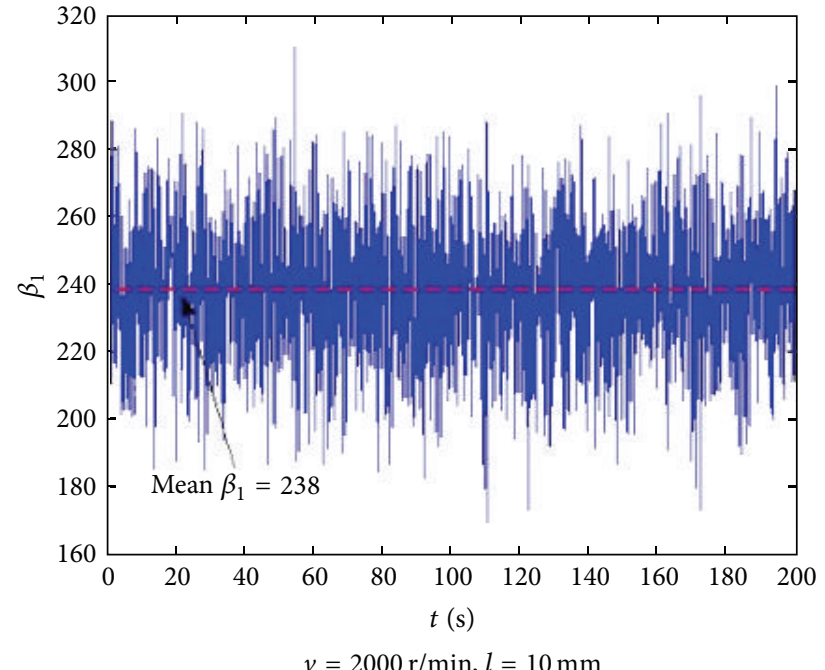

(b)

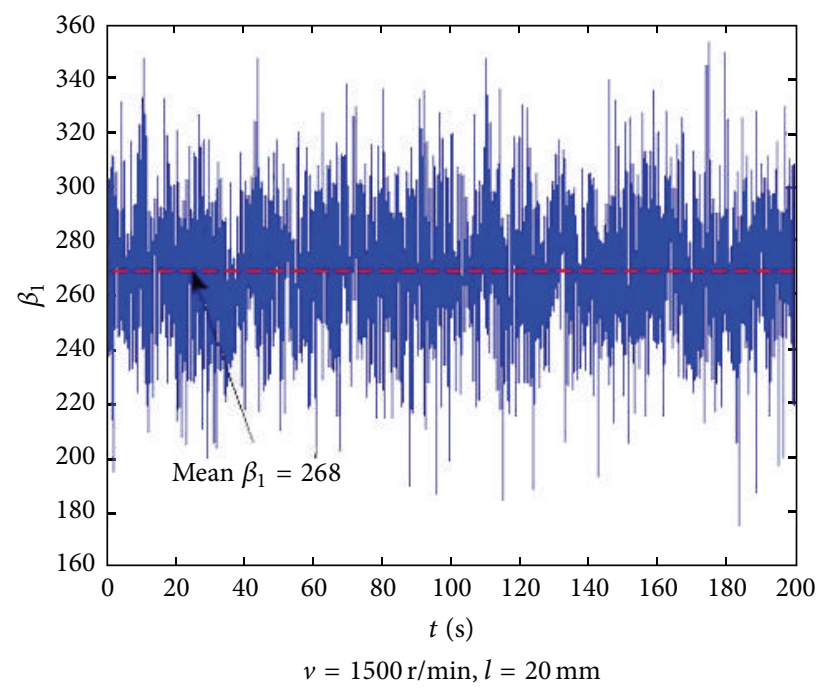

(c)

FIGURE 6: Evolution curves of 1-dimensional Betti numbers.

at an average stirring rate $\bar{v}$ of $100 \mathrm{r} / \mathrm{min}$ and $1000 \mathrm{r} / \mathrm{min}$, as shown in Figures 3 and 4, respectively. We can conclude that, when the electric current is within $0-0.5 \mathrm{~A}$, the electrical field exerts a little impact on the flow field and can therefore be ignored.

Thus, in this experiment the effect of electrical field is neglected. The electric current is kept at $0.25 \mathrm{~A}$. Different average rotating speeds of $500 \mathrm{r} / \mathrm{min}, 1000 \mathrm{r} / \mathrm{min}, 1500 \mathrm{r} / \mathrm{min}$, $2000 \mathrm{r} / \mathrm{min}, 2500 \mathrm{r} / \mathrm{min}$, and $3000 \mathrm{r} / \mathrm{min}$ were used to conduct the experiments. The vertical distance from the paddle to the bottom of the tank was set in a range between 0 and $30 \mathrm{~mm}$.

\subsection{Evaluation of Micron-Particle Aggregation Homogeneity.} First, data from different mixing conditions were collected. A high-speed camera stored the real-time flow field images with a stirring time of $200 \mathrm{~s}$. Second, digital image processing technology was used to process each real-time image of mixing particles in flow field into a binary image. Finally, using the CHomP program, Betti numbers were calculated from the binary images. Curves of 0-dimensional and 1-dimensional Betti numbers as a function of time $T$ are obtained. These Betti numbers curves were then evaluated to extract the minimum average mixing time $T$, the average 0 -dimensional and 1-dimensional Betti numbers, and the amplitude $A$. The detailed calculated data are shown in Table 2.

Based on a previous study [25], we define the objective function in the mixing effect evaluation model as

$$
\begin{gathered}
\text { Min: } \Phi(V, l)=\frac{\overline{\beta_{1}}}{\overline{\beta_{0}}} \times T \times V \times A \\
\overline{\beta_{0}} \geq \frac{\left(\max \overline{\beta_{0}}+\min \overline{\beta_{0}}\right)}{2},
\end{gathered}
$$




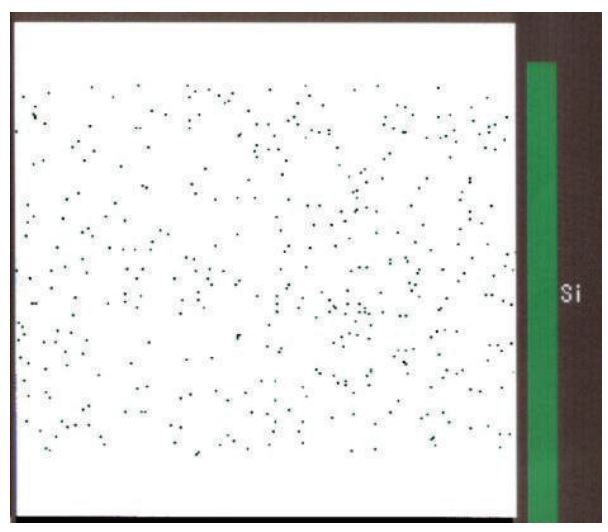

$v=1000 \mathrm{r} / \mathrm{min}, h=10 \mathrm{~mm}$

(a)

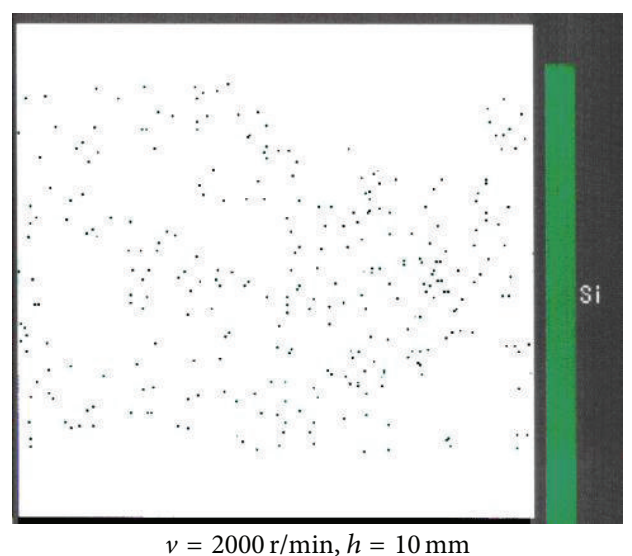

(b)

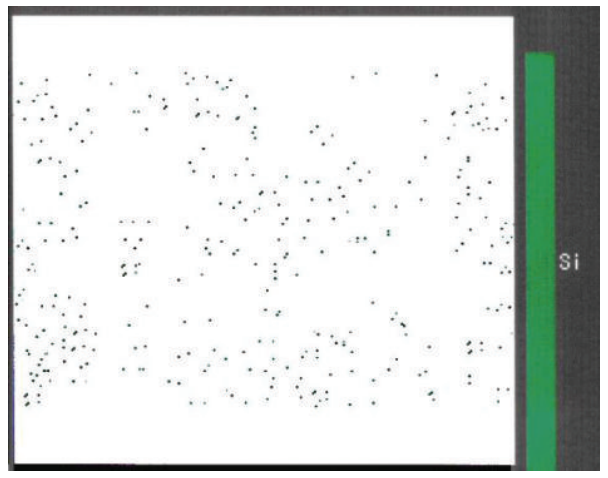

$v=1500 \mathrm{r} / \mathrm{min}, h=20 \mathrm{~mm}$

(c)

FIgURE 7: Content distribution of $\mathrm{SiO}_{2}$ in composite coatings using an electron probe.

TABLE 2: Data of minimum mixing time, average 0 -dimensional and 1-dimensional Betti numbers, and amplitude at different rotating speeds and paddle heights with $I=0.25$ A.

\begin{tabular}{ccccccc}
\hline \multirow{2}{*}{$\mathrm{mm}$} & 500 & 1000 & 1500 & 2000 & 2500 & 3000 \\
\hline 10 & & & & & & \\
$\overline{\beta_{0}}$ & 1121 & 1398 & 1364 & 1402 & 1327 & 1362 \\
$\overline{\beta_{1}}$ & 156 & 212 & 245 & 238 & 219 & 189 \\
$T$ & 75 & 21 & 20 & 24 & 18 & 16 \\
$A$ & 20 & 23 & 21 & 22 & 16 & 17 \\
\hline 20 & & & & & & \\
$\overline{\beta_{0}}$ & 1167 & 1339 & 1400 & 1322 & 1301 & 1345 \\
$\overline{\beta_{1}}$ & 184 & 176 & 268 & 251 & 204 & 198 \\
$T$ & 68 & 25 & 27 & 19 & 22 & 18 \\
$A$ & 23 & 25 & 26 & 25 & 17 & 16 \\
\hline 30 & & & & & & \\
$\overline{\beta_{0}}$ & 1110 & 1295 & 1308 & 1347 & 1289 & 1289 \\
$\overline{\beta_{1}}$ & 235 & 221 & 226 & 188 & 171 & 171 \\
$T$ & 65 & 28 & 19 & 20 & 31 & 31 \\
$A$ & 27 & 23 & 22 & 19 & 16 & 16 \\
\hline
\end{tabular}

where $\overline{\beta_{0}}$ is the average of the 0 -dimensional Betti numbers, $\overline{\beta_{1}}$ the average of the 1-dimensional Betti numbers, $V$ is the rotating rate, $T$ is the minimum mixing time, and $A$ is the amplitude. In this model, $V$ replaces the gas flow rate in the multiphase flow.

The optimal mixing-effect conditions, calculated from the evaluation model, were $v=1000 \mathrm{rmp}, h=10 \mathrm{~mm}$, and $I=0.25 \mathrm{~A}$. We compare and analyze another two sets of coating conditions with relatively better mixing effects $(v=$ $2000 \mathrm{r} / \mathrm{min}, h=10 \mathrm{~mm} ; v=1500 \mathrm{r} / \mathrm{min}, h=20 \mathrm{~mm}$ ) to investigate the micron-particle aggregation's influence on the coating material's capabilities.

Figure 5 shows the 0-dimensional and 1-dimensional Betti number curves as a function of time, $T$, for this experiment. The red dotted line indicates the average values. The 0-dimensional Betti number curve depicts the effective quantification of mixing homogeneity.

Figure 6 depicts the 1-dimensional Betti number evolution curves, which represent the effective quantification of mixing heterogeneity.

First, an electron probe was used to determine the $\mathrm{SiO}_{2}$ content distribution. The results are compared in Figure 7. It can be seen that $\mathrm{SiO}_{2}$ is well distributed at the optimal condition. However, there is clearly some empty area in another two, which proves that the flow field mixing is not so balanced. However, there is clearly some empty area in another two Figures 7(b) and 7(c).

Secondly, acid was used to dissolve the coating metal to weigh the rest of the mass of $\mathrm{SiO}_{2}$. The amount of $\mathrm{SiO}_{2}$ in 
TABLE 3: $\mathrm{SiO}_{2}$ content (mass \%), thickness, and erosion resistance of composite coatings in different areas of iron plate for $v=1000 \mathrm{r} / \mathrm{min}$ and $h=10 \mathrm{~mm}$.

\begin{tabular}{lccc}
\hline Sample no. & $\begin{array}{c}\mathrm{SiO}_{2} \\
\text { content [\%] }\end{array}$ & Thickness $[\mu \mathrm{m}]$ & $\begin{array}{c}\text { Red rust time } \\
\text { in NSS [h] }\end{array}$ \\
\hline 1 & $0.49 / 0.47$ & $21.5 / 22.5$ & $432 / 448$ \\
2 & $0.51 / 0.49$ & $20.6 / 21.2$ & $416 / 432$ \\
3 & $0.50 / 0.49$ & $22.5 / 22.0$ & $448 / 432$ \\
4 & $0.52 / 0.50$ & $21.2 / 21.8$ & $416 / 432$ \\
5 & $0.53 / 0.51$ & $20.5 / 20.8$ & $416 / 416$ \\
6 & $0.52 / 0.52$ & $22.0 / 21.4$ & $432 / 416$ \\
7 & $0.54 / 0.53$ & $21.5 / 22.4$ & $432 / 448$ \\
8 & $0.56 / 0.55$ & $21.2 / 22.1$ & $416 / 432$ \\
9 & $0.56 / 0.54$ & $22.4 / 22.2$ & $448 / 448$ \\
\hline
\end{tabular}

TABLE 4: $\mathrm{SiO}_{2}$ content (mass \%), thickness, and erosion resistance of composite coatings in different areas of iron plate for $v=2000 \mathrm{r} / \mathrm{min}$ and $h=10 \mathrm{~mm}$.

\begin{tabular}{lccc}
\hline Sample no. & $\begin{array}{c}\mathrm{SiO}_{2} \\
\text { content [\%] }\end{array}$ & Thickness $[\mu \mathrm{m}]$ & $\begin{array}{c}\text { Red rust time } \\
\text { in NSS [h] }\end{array}$ \\
\hline 1 & $0.39 / 0.38$ & $18.3 / 18.4$ & $390 / 406$ \\
2 & $0.43 / 0.41$ & $22.3 / 22.1$ & $409 / 425$ \\
3 & $0.39 / 0.38$ & $19.7 / 20.1$ & $396 / 412$ \\
4 & $0.62 / 0.60$ & $21.2 / 21.8$ & $412 / 428$ \\
5 & $0.53 / 0.51$ & $20.4 / 20.7$ & $416 / 432$ \\
6 & $0.36 / 0.38$ & $18.8 / 19.2$ & $400 / 416$ \\
7 & $0.51 / 0.50$ & $22.5 / 22.3$ & $402 / 402$ \\
8 & $0.64 / 0.62$ & $20.6 / 21.1$ & $448 / 448$ \\
9 & $0.41 / 0.39$ & $18.2 / 18.5$ & $389 / 405$ \\
\hline
\end{tabular}

different areas of the composite coating was determined by dividing the $\mathrm{SiO}_{2}$ mass by the total weight of the coating before dissolution. Then, a magnetic thickness tester was used to measure the thickness at different areas of 9 welldistributed coatings. Finally, the samples were wax-sealed after drying and tested for ageing by exposing an area of size $20 \times 20 \mathrm{~mm}$ to air and placing into a salt and fog box. When the temperature in the box reached the predetermined testing temperature, a continuous spray was applied. During the spraying process, we observed and recorded the erosion of the sample's surface during a certain time. The terminating time occurred when red rust was observed on the sample. To more accurately compare each sample's time and erosion-resisting capability, three test pieces of each sample were taken, and the average values calculated, as shown in Table 3.

Table 3 indicates that, when the content of $\mathrm{SiO}_{2}$ is maintained between 0.47 and $0.56 \%$ (mass), the thickness of the coating remains at $20-30 \mu \mathrm{m}$ and the time for red rust to appear is over 410 hours. This is compared to other experiments using the same thickness of zinc coating where the rust time is a maximum of 280 hours [11, 12]. Relative capability tests were performed for uneven distributions. The results, shown in Tables 4 and 5, indicate that there is a big
TABLE 5: $\mathrm{SiO}_{2}$ content (mass \%), thickness, and erosion resistance of composite coatings in different areas of iron plate for $v=1500 \mathrm{r} / \mathrm{min}$ and $h=20 \mathrm{~mm}$.

\begin{tabular}{lccc}
\hline Sample no. & $\begin{array}{c}\mathrm{SiO}_{2} \\
\text { content [\%] }\end{array}$ & Thickness $[\mu \mathrm{m}]$ & $\begin{array}{c}\text { Red rust time } \\
\text { in NSS [h] }\end{array}$ \\
\hline 1 & $0.64 / 0.61$ & $23.3 / 23.5$ & $401 / 417$ \\
2 & $0.50 / 0.52$ & $21.4 / 21.2$ & $410 / 408$ \\
3 & $0.34 / 0.37$ & $18.6 / 18.7$ & $386 / 392$ \\
4 & $0.62 / 0.60$ & $22.3 / 22.5$ & $432 / 416$ \\
5 & $0.55 / 0.53$ & $21.5 / 21.8$ & $432 / 432$ \\
6 & $0.37 / 0.39$ & $18.9 / 20.1$ & $388 / 398$ \\
7 & $0.45 / 0.43$ & $20.5 / 20.3$ & $393 / 409$ \\
8 & $0.51 / 0.50$ & $21.3 / 21.1$ & $409 / 425$ \\
9 & $0.61 / 0.59$ & $23.8 / 23.6$ & $432 / 416$ \\
\hline
\end{tabular}

disparity among the 9 points, which leads to a bad overall performance.

In summary, using an electron probe and performance analysis of the coatings, we can conclude that, when the micron-particle aggregation around the negative electrode benefits from an optimal mixing effect, the $\mathrm{SiO}_{2}$ particles are well-distributed and the red rust time in the salt spray test is maintained at over 410 hours; after comparing the capability tests, under other relatively good mixing conditions, their testing points' capabilities show a large variation, and the overall performance is not as good as the optimal condition where $h=10 \mathrm{~mm}$ and $v=1000 \mathrm{r} / \mathrm{min}$. Meanwhile, the micron-particle aggregation is omnipresent in the whole stirring process. Betti numbers are used to quantify the micron-particle aggregation and to explore its effect on the coating capabilities.

\section{Conclusion}

A composite $\mathrm{Zn}-\mathrm{SiO}_{2}$ electrodeposition system and the most widely used stirring method are adopted to explore the flowing characteristics of the electrolyte. In particular, digital image processing technology is used to analyze images of the micron particles' distribution and aggregation. Meanwhile, the Betti numbers method is used to quantify the mixing effects of the composite electrolyte. The 0-dimensional Betti numbers $\left(\beta_{0}\right)$ are used to estimate the number of micron particles in the images, and the evolution of $\beta_{0}$ indicates an important parameter $T$, which is the minimum average mixing time. The 1-dimensional Betti numbers are introduced to characterize the nonhomogeneity of the mixture. It was shown that the effects of micron-particle aggregation on the performance of zinc-silica composite coatings can be assessed using the Betti numbers method.

A comparison of the coatings' performance with relatively good mixing effects is conducted with the assistance of electron probe testing, a thickness tester, and an erosion test. Results show that, under other conditions, there is a big disparity between the 9 testing points and this shows that the overall performance of these conditions are inferior to the optimal condition. This paper verifies the feasibility of 
the Betti numbers method and model. It will further improve studies of composite electrodeposition fluid mechanics, which provides an important reference to understand the basic scientific questions of electrodeposition and its process optimization.

\section{Acknowledgments}

This work is supported by the Joint Funds of National Natural Science Foundation of China (Grant no. U0937604), the National Natural Science Foundation of china (Grant no. 51361018), and the Nature Science Foundation of Yunnan Province (nos. 2013FB020 and KKSY201258156). The authors wish to especially thank the referees for detailed questions and comments that greatly improved the presentation.

\section{References}

[1] Z. Shahri, S. R. Allahkaram, and A. Zarebidaki, "Electrodeposition and characterization of Co-BN (h) nanocomposite coatings," Applied Surface Science, vol. 276, pp. 174-181, 2013.

[2] F. Su, C. Liu, J. Guo, and P. Huang, "Characterizations of nanocrystalline Co and Co/MWCNT coatings produced by different electrodeposition techniques," Surface and Coatings Technology, vol. 217, pp. 94-104, 2013.

[3] M. Zielinski, "Effects of constant magnetic field on the electrodeposition reactions and cobalt-tungsten alloy structure," Materials Chemistry and Physics, vol. 141, no. 1, pp. 370-377, 2013.

[4] A. Krause, M. Uhlemann, A. Gebert, and L. Schultz, "The effect of magnetic fields on the electrodeposition of cobalt," Electrochimica Acta, vol. 49, no. 24, pp. 4127-4134, 2004.

[5] Q. Qu, C. Yan, L. Zhang et al., "Initial atmospheric corrosion of zinc sprayed with NaCl," Transactions of Nonferrous Metals Society of China, vol. 13, pp. 1243-1246, 2003.

[6] R. Ramanauskas, L. Muleshkova, L. Maldonado, and P. Dobrovolskis, "Characterization of the corrosion behaviour of $\mathrm{Zn}$ and Zn alloy electrodeposits: atmospheric and accelerated tests," Corrosion Science, vol. 40, no. 2-3, pp. 401-410, 1998.

[7] B. Tom, "Towards a universal surface engineering road map," Surface Engineering, vol. 16, pp. 89-90, 2000.

[8] T. Bellezze, G. Roventi, and R. Fratesi, "Electrochemical study on the corrosion resistance of Cr III-based conversion layers on zinc coatings," Surface and Coatings Technology, vol. 155, no. 2-3, pp. 221-230, 2002.

[9] H. Wang and C. Z. Chen, "Current situation of the study on zinc plating passivation tier," Agricultural Equipment and Vehicle Engineering, vol. 12, pp. 28-30, 2008 (Chinese).

[10] Y. B. Huang, "Outline about passivating methods of galvanizing," Coatings Painting and Electroplating, vol. 5, pp. 33-37, 2007 (Chinese).

[11] Y. Fan, Y. Zhang, and P. Dong, "Research on zinc-silica composite plating," Advanced Materials Research, vol. 79-82, pp. 19031906, 2009.

[12] Y. Fan, J. Xu, Y. Jiang, and W. Wang, "Numerical simulation and PIV test on flow-field character of zinc-silica composite electrolyte," Materials Science Forum, vol. 704-705, pp. 440-445, 2012.

[13] T. R. Khan, A. Erbe, M. Auinger, F. Marlow, and M. Rohwerder, "Electrodeposition of zinc-silica composite coatings: challenges in incorporating functionalized silica particles into a zinc matrix," Science and Technology of Advanced Materials, vol. 12, no. 5, Article ID 055005, 2011.

[14] F. Xia, H. Xu, C. Liu, J. Wang, J. Ding, and C. Ma, "Microstructures of Ni-AlN composite coatings prepared by pulse electrodeposition technology," Applied Surface Science, vol. 271, pp. 7-11, 2013.

[15] S.-K. Kim and T.-S. Oh, "Electrodeposition behavior and characteristics of Ni-carbon nanotube composite coatings," Transactions of Nonferrous Metals Society of China, vol. 21, no. 1, pp. S68-S72, 2011.

[16] X. Xia, I. Zhitomirsky, and J. R. McDermid, "Electrodeposition of zinc and composite zinc-yttria stabilized zirconia coatings," Journal of Materials Processing Technology, vol. 209, no. 5, pp. 2632-2640, 2009.

[17] M. Abe, Y. Shiohara, T. Adaniya, and H. Naemura, "Composite zinc-silica electro-galvanised steel sheet with excellent corrosion resistance," United States Patent US4839241 A, 1989.

[18] T. J. Tuaweri and G. D. Wilcox, "Behaviour of $\mathrm{Zn}-\mathrm{SiO}_{2}$ electrodeposition in the presence of N,N-dimethyldodecylamine," Surface and Coatings Technology, vol. 200, no. 20-21, pp. 59215930, 2006.

[19] S.-H. Hwang, S.-C. Jung, S.-M. Yoon, and D.-K. Kim, "Preparation and characterization of dye-intercalated $\mathrm{Zn}$-Al-layered double hydroxide and its surface modification by silica coating," Journal of Physics and Chemistry of Solids, vol. 69, no. 5-6, pp. 1061-1065, 2008.

[20] G. A. Gottwald and I. Melbourne, "Testing for chaos in deterministic systems with noise," Physica D, vol. 212, no. 1-2, pp. 100-110, 2005.

[21] G. A. Gottwald and I. Melbourne, "A new test for chaos in deterministic systems," Proceedings of the Royal Society A, vol. 460, no. 2042, pp. 603-611, 2004.

[22] G. A. Gottwald and I. Melbourne, "Comment on "reliability of the 0-1 test for chaos"'” Physical Review E, vol. 77, no. 2, Article ID 028201, 2008.

[23] I. Falconer, G. A. Gottwald, I. Melbourne, and K. Wormnes, "Application of the 0-1 test for chaos to experimental data," SIAM Journal on Applied Dynamical Systems, vol. 6, no. 2, pp. 395-402, 2007.

[24] CHomP, http://chomp.rutgers.edu/software/.

[25] J. Xu, H. Wang, and H. Fang, "Multiphase mixing quantification by computational homology and imaging analysis," Applied Mathematical Modelling, vol. 35, no. 5, pp. 2160-2171, 2011. 

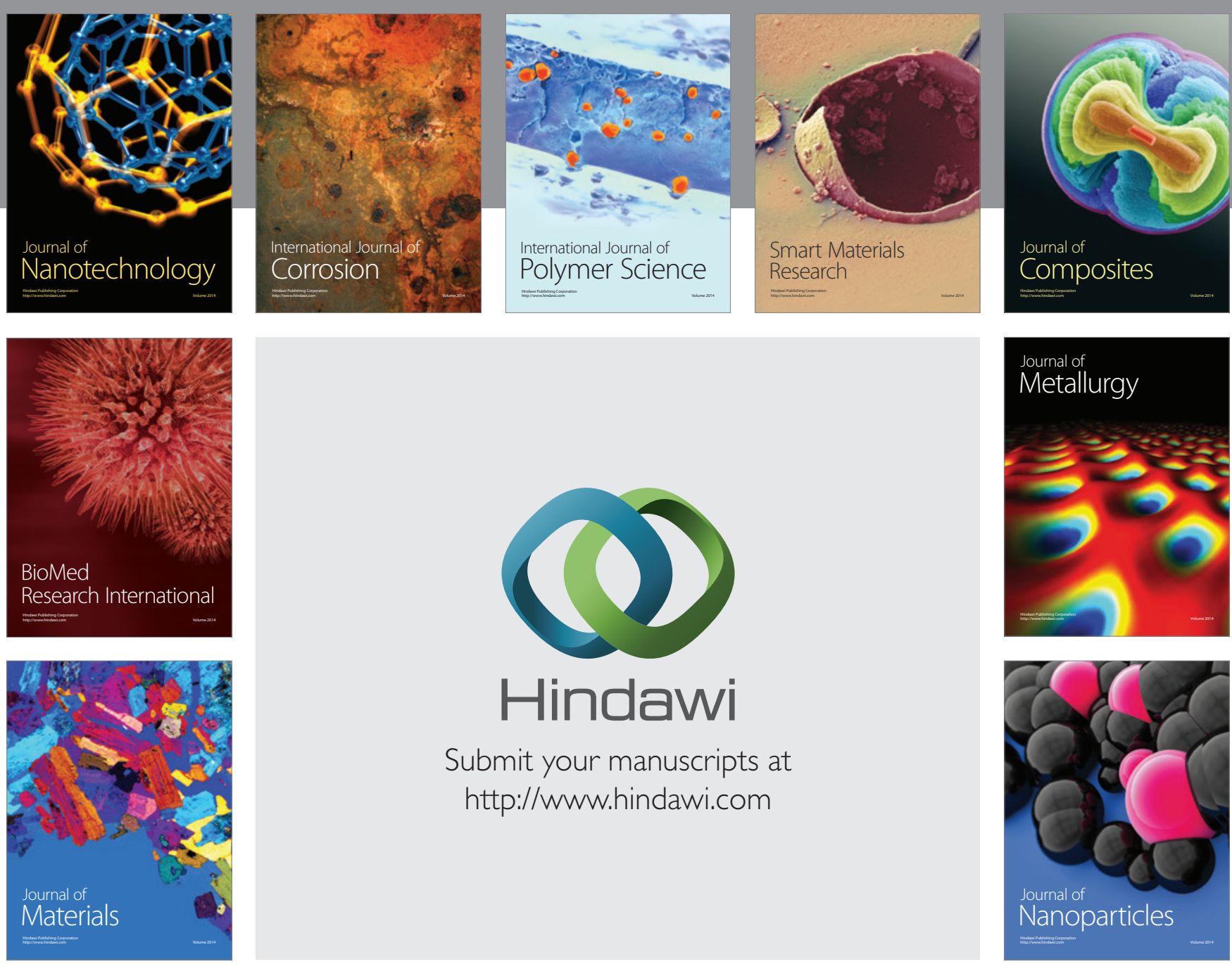

Submit your manuscripts at http://www.hindawi.com
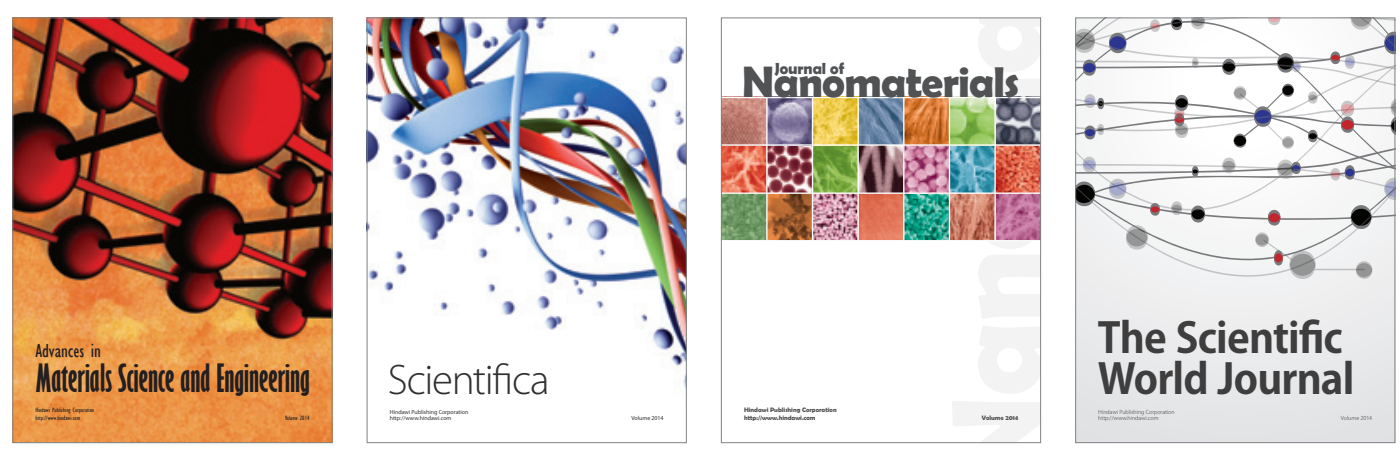

\section{The Scientific World Journal}
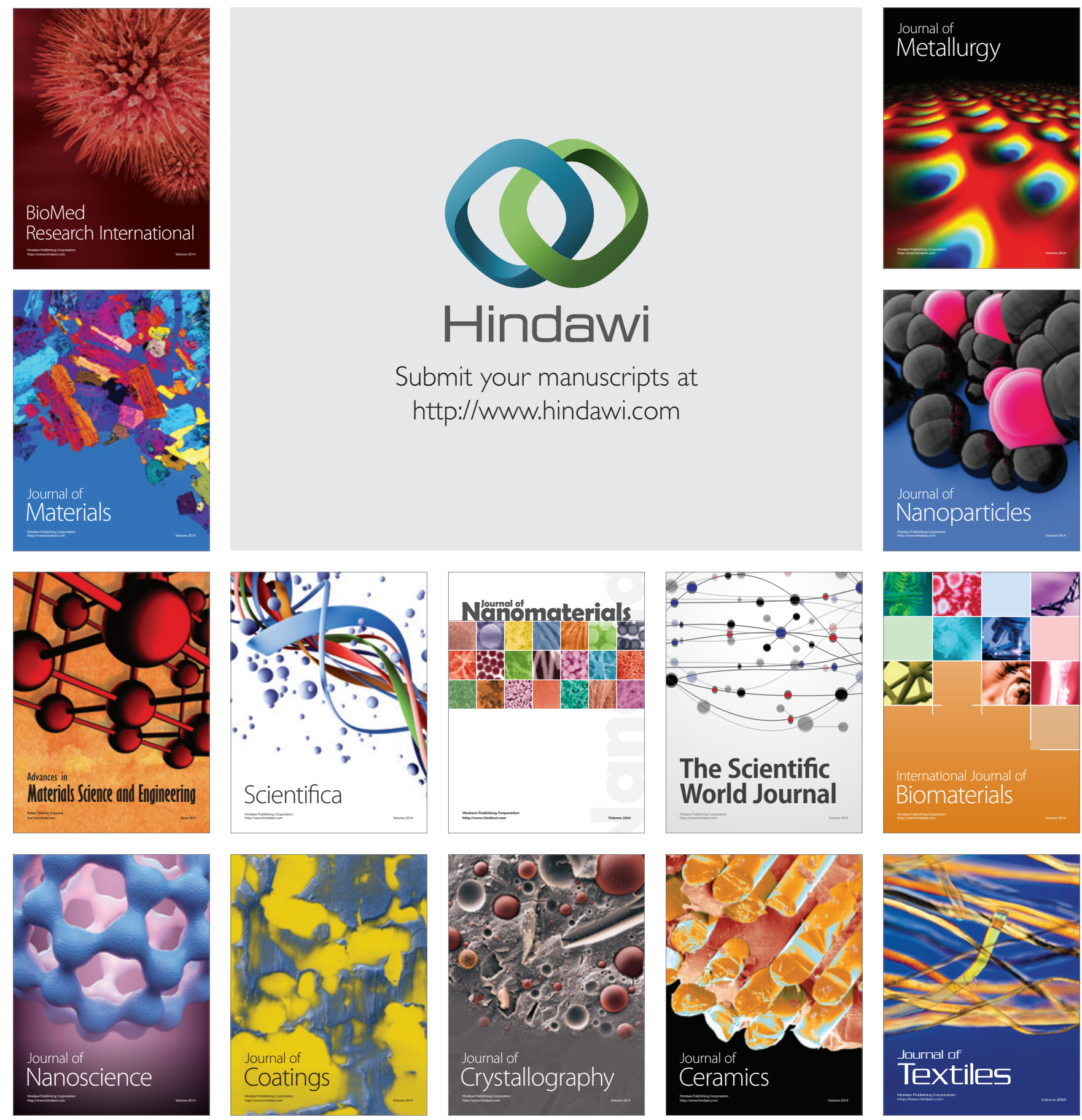